\title{
Measurement of Alkaline Phosphatase Isoenzyme in Different Stages of Bilharzial Liver Affection
}

\author{
Laila Hussein, ${ }^{1, *}$ Sohair M. Abdel Gani, ${ }^{2}$ and Somaya ShaAban ${ }^{3}$ \\ ${ }^{1}$ Department of Nutrition, National Research Centre, Giza, Egypt \\ ${ }^{2}$ Tropical Disease Unit, Faculty of Medicine for Girls, \\ Al-Azhar University, Cairo, Egypt \\ ${ }^{3}$ Department of Nutrition and Health Education Center, \\ Ministry of Public Health, Cairo, Egypt
}

(Received February 13, 1990)

\begin{abstract}
Summary The present study comprised 22 normal subjects and 30 bilharzial patients. The patients were categorized into groups I, II, and III according to the stage of liver affection and the absence or presence of ascitis. Total plasma alkaline phosphatase (AP) was assayed by use of the substrate naphthyl phosphate, and the liver isoenzyme activity of AP was also investigated after treatment of the plasma with L-phenylalanine, which inhibits the AP fraction of intestinal origin (LPSAP). The activity measured in the presence of L-phenylalanine thus represents that attributable to plasma AP of liver origin. Respective mean activities of 47 and 41 and 78 and 72 units/liter were obtained for total and AP isoenzyme of liver origin in the plasma of normal and bilharzial patients with hepatosplenomegaly and ascitis (group III), respectively. The liver fraction represented 87.2 and $92.3 \%$ of total plasma AP among normal and bilharzial patients (group III), respectively.
\end{abstract}

Key Words: bilharzial patients, plasma alkaline phosphatase isoenzyme

Schistosomes are parasitic helminths that infect man and his domestic animals. It is currently estimated that 200 million people are infected with Schistosomes throughout the tropical regions of the world [1]. Schistosomal infection of the liver results in fibrosis and absence of parenchymal regeneration [2] and is reflected by changes in the activities of some liver enzymes circulating in the blood stream. Hyperphosphatasemia in liver diseases has made the serum alkaline phosphatase (AP) determination the most frequently requested enzyme assay for over 50 years.

\footnotetext{
*To whom correspondence should be addressed.
} 
Sites of alkaline phosphatase activity are frequently in endothelial cells of blood capillaries, mucous glandular cells [3], microvilli of the intestines [4], bile canaliculi [5], placenta [6] as well as the brush border of the luminal surface of epithelial cells of the proximal convoluted renal tubules [7]. Identification of the tissue origin of AP isoenzymes in human serum is clinically of great importance. Identification of the tissue source of AP may be accomplished by various techniques including L-phenylalanine inhibition $[8,9]$. The activity measured in the presence of the inhibitor L-phenylalanine reflects that of AP isoenzymes of liver and bone origins, whereas the activity measured in the presence of its stereoisomer, D-phenylalanine, measures total activity. The difference between the results with Dand L-phenylalanine represent L-phenylalanine-sensitive AP (LPSAP), which is practically almost all of intestinal origin [8].

The present report describes the activities of total and liver AP isoenzymes in the plasma of bilharzial patients with different degrees of liver affection.

\section{MATERIALS AND METHODS}

Patients. The study included thirty patients (16 males and 14 females) ranging in age from 19 to 70 years (mean $30.5 \pm 3$ years). The patients were subjected to thorough clinical examination and to routine laboratory investigations including stool and urine analysis, blood chemistry, and sigmoidoscopy.

Based upon the findings obtained from the above-mentioned tests, the patients were divided into 3 groups, each consisting of 10 patients. Group I consisted of patients with early Schistosoma infection; Group II, those infected patients with hepatomegaly (100\%) and/or splenomegaly (80\%); and Group III, those infected patients with ascitis plus hepatosplenomegaly. Twenty-two age-matched healthy subjects of both sexes served as the control.

Collection of blood. After an overnight fast, venous blood specimens were drawn from all subjects into clean glass tubes containing a few milligrams of EDTA as anticoagulant. The samples were centrifuged immediately in the cold at $3,000 \mathrm{rpm}$ for $15 \mathrm{~min}$ in a clinical centrifuge and the plasma was separated for further enzymatic assays.

Assay methods. Plasma AP was assayed according to the method of Fishman and Ghosh [8]. Plasma was incubated for one hour at $37^{\circ} \mathrm{C}$ with carbonate buffer, pH 9.3 containing disodium $\beta$-naphthyl phosphate at respective final concentrations of $0.05 \mathrm{M}$ and $0.018 \mathrm{M}$. The incubation mixture also contained $0.005 \mathrm{M}$ concentration of either $\mathrm{L}-$ or D-phenylalanine. The enzymatic hydrolysis was arrested by addition of $0.4 \mathrm{ml}$ of $20 \%$ trichloroacetic acid. After centrifugation, the clear protein-free supernatant $(1.2 \mathrm{ml})$ was treated with $0.2 \mathrm{ml}$ of ammonium molybdate solution (5\%), $0.2 \mathrm{ml}$ hydroquinone (1\%), and $0.2 \mathrm{ml}$ sodium sulphite (20\%) with intermittent mixing in between [10]. The resultant blue colour of the solution was stable up to $1 \mathrm{~h}$, and its optical density was measured within that time with a spectrophotometer at $650 \mathrm{~nm}$. The results of AP activity were expressed as 
$\mu$ moles of inorganic phosphorus liberated $/ \mathrm{min} / \mathrm{ml}$.

Plasma albumin was estimated by the bromocresol green method [11].

Plasma alanine aminotransferase activity and plasma bilirubin level were also estimated by use of diagnostic kits (Boehringer, Mannheim, West Germany).

\section{RESULTS}

Table 1 presents relevant biochemical data obtained with sera from bilharzial patients and normal subjects. We found that out of 30 bilharzial patients, 14 (47\%) had a low plasma albumin level $(<3.5 \mathrm{~g} / \mathrm{dl}), 5(17 \%)$ had elevated serum bilirubin $(>1.5 \mathrm{mg} / \mathrm{dl}), 10 \%$ showed increased serum alanine aminotransferase ( $>18$ units/ liter) and $40 \%$ displayed an increase in alkaline phosphatase activity (760 units/ liter).

Total plasma AP fluctuated between 32.5-66.9 with a mean level of $49.1 \pm 3.0$ units/liter among the normal males. Respective activities ranging between 33.459.5 and mean level of $44.9 \pm 2.3$ units/liter were obtained among the normal females. Plasma AP activity of intestinal origin (LPSAP) did not exceed 7-8 units/ liter; whereas the plasma AP activity measured in the presence of L-phenylalanine, which represents the sum of activities of liver and bone isozymes ranged between 28.1-61.9 units/liter among normals of both sexes, with mean activities of 43.6士 3.2 and $39.3 \pm 2.2$ units/liter for normal males and females, respectively.

All bilharzial patients showed elevated mean values for AP compared with the mean control figures. However, the increase reached a significant difference $(p<0.05)$ only among patients belonging to group III (Table 1). Among this group total and AP fraction of liver origin ranged between 53.7-92.5 and 52.9-88.3 units/ liter, respectively. In 55\% of bilharzial patients belonging to group III, the liver fraction made up more than $90 \%$ of the total plasma AP activity. Mean activities of $8.3 \pm 1.5,15.9 \pm 1.2$, and $9.9 \pm 1.0$ units/liter were obtained for LPSAP (plasma

Table 1. Mean blood chemistry and different isozymes of plasma AP in control subjects and bilharzial patients.

\begin{tabular}{|c|c|c|c|c|c|}
\hline \multirow[b]{2}{*}{ Parameter } & \multirow[b]{2}{*}{$\begin{array}{c}\text { Normals } \\
(n=22)\end{array}$} & \multicolumn{3}{|c|}{ Diseased groups } & \multirow[b]{2}{*}{$\begin{array}{l}\text { All patients } \\
\quad(n=30)\end{array}$} \\
\hline & & $\begin{array}{c}\mathrm{I} \\
(n=10)\end{array}$ & $\begin{array}{c}\text { II } \\
(n=10)\end{array}$ & $\begin{array}{c}\text { III } \\
(n=10)\end{array}$ & \\
\hline Age & $30.0 \pm 2$ & $17.7 \pm 3.80$ & $27.2 \pm 6.00$ & $46.5 \pm 7.00$ & 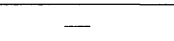 \\
\hline Albumin (g/dl) & $4.6 \pm 0.16^{\mathrm{b}}$ & $3.5 \pm 0.19^{\mathrm{a}}$ & $3.8 \pm 0.20^{\mathrm{a}}$ & $3.2 \pm 0.16^{\mathrm{a}}$ & $3.5 \pm$ \\
\hline Bilirubin $(\mathrm{mg} / \mathrm{dl})$ & $0.5 \pm 0.04^{\mathrm{a}}$ & $0.8 \pm 0.09^{b}$ & $0.8 \pm 0.10^{\mathrm{b}}$ & $1.6 \pm 0.20^{c}$ & $1.1 \pm($ \\
\hline ALAT (units/liter) & $8.7 \pm 0.58^{a}$ & $11.7 \pm 1.20^{\mathrm{a}, \mathrm{b}}$ & $11.7 \pm 1.10^{\mathrm{a}, \mathrm{b}}$ & $18.7 \pm 1.70^{c}$ & $13.8 \pm 1.60^{\mathrm{b}, \mathrm{c}}$ \\
\hline \multicolumn{6}{|l|}{ AP (units/liter) } \\
\hline Total value & $47.0 \pm$ & $53.4 \pm 9.62^{\mathrm{a}, \mathrm{b}}$ & $52.8 \pm 6.68$ & $77.7 \pm 4.68^{c}$ & $64.6 \pm$ \\
\hline Liver isoenz & $41.4 \pm 1.96^{\mathrm{a}}$ & $47.2 \pm 9.28^{\mathrm{a}, \mathrm{b}}$ & $46.6 \pm 6.20^{\mathrm{a}, \mathrm{b}}$ & $70.8 \pm 4.78^{c}$ & $57.7 \pm 4.25^{\mathrm{b}, \mathrm{c}}$ \\
\hline Intestinal LPSAP & $7.2 \pm 0.69^{a}$ & $8.3 \pm 1.50^{\mathrm{a}, \mathrm{b}}$ & $15.9 \pm 1.20^{c}$ & $9.9 \pm 1.04^{\mathrm{a}, \mathrm{b}}$ & $11.3 \pm 1.16^{\mathrm{b}, \mathrm{c}}$ \\
\hline
\end{tabular}

Values: mean \pm SE. Mean values are significantly different $(p<0.05)$ if they don't share the same letter within the same row (Student's $t$-test).

Vol. 9, No. 3, 1990 
AP of intestinal origin) among bilharzial patients with liver diseases belonging to groups I, II, and III, respectively. The mean LPSAP activity obtained for group II was significantly higher $(p<0.05)$ than that found for either the control or the other diseased groups.

\section{DISCUSSION}

Measurement of serum AP activity has been performed particularly for the diagnosis of bone and hepatobiliary diseases. Using polyacrylamide gel electrophoresis with densitometric scanning combined with two-point heat inactivation, Steinberg and Rogers [12] assayed total and liver AP isoenzyme in serum of normal subjects. The authors reported mean activities of 72.4 and 33.0 and 60.7 and 30.4 units/liter for total and liver AP among normal men and women, respectively. Our figures are quite overlapping with the above-mentioned AP liver activities; though total AP obtained in the present work tended to be lower among normal subjects. From a study using wheat germ lectin affinity electrophoretic separation Kuwana et al. [13] recently reported the reference limits of total and liver AP isoenzyme in 488 healthy Japanese. Mean figures of 116 and 38 and 141 and 50 units/liter were reported by those authors for total and liver AP activities among healthy females and males (40-49 years of age), respectively.

Our results are in agreement with those published previously by Salah et al. [14], who reported a more than twofold increase in the AP activity among patients with schistosomiasis tested upon admission: mean activity of 1.5 units/liter for controls vs. 3.7 units/liter bilharzial patients.

Further, the addition of L-phenylalanine to the enzymatic assay for inhibition of intestinal AP was described many years ago. Fishman and Ghosh [8] reported mean activities of 8.6, 6.9 (80\% of total), and 1.6 (18.6\%) King Armstrong AP units/dl in the serum of normal subjects for total, non-LPSAP, and LPSAP isoenzymes, respectively. Respective mean activities obtained for cirrhotic patients were $32.5,23.4(72 \%)$, and 9.1 (28\%). The results obtained in the present work with bilharzial patients with liver disease showed clearly that only patients with ascitis had significantly higher total AP and liver AP isoenzyme activities $(p<0.05)$ compared with all other groups. This finding, i.e., the increased liver AP activity in blood plasma, suggests the pathological involvement of the parenchymous liver or bile mucosal cells due to a direct effect or due to a toxic or inflammatory reaction, any of which may cause an increased enzyme efflux from these cells.

\section{REFERENCES}

1. Simpson, A.J., Ali, P.O., Yi, X.O., and Smithers, S.R. (1988): Schistosome glycoconjugates as antigens and their relevance in experimental and human Schistosomiasis. Biochem. Soc. Trans., 16, 264-267.

2. Salah, M. (1962): The bilharzial liver. Alexandria Med. J., 8, 3-10. 
3. Fischer, E. (1966): Alkaline inorganic pyrophosphates in the mucous glandular cells. Acta Biol. Acad. Sci. Hung., 17, 159-165.

4. Daems, W.T., and Persijn, J.P. (1965): Enzyme histochemistry in electron microscopy, in Enzymes, in Clinical Chemistry, ed. by Ruyssen and Vandendriesche, pp. 75-103.

5. Frankel, H.H., and Peters, R.L. (1964): A modified calcium cobalt method for the demonstration of alkaline phosphatase. Am. J. Clin. Pathol., 42, 324-327.

6. Wachstein, M., Meagher, J.G., and Ortiz, J.M. (1963): Enzymatic histochemistry of the term human placenta. Am. J. Obstet. Gynecol., 87, 13-26.

7. Wachstein, M., and Bradshaw, M. (1965): Histochemical localization of enzyme activity in the kidneys of 3 mammalian species during their post natal development. J. Histochem. Cytochem., 13, 44-56.

8. Fishman, W.H., and Ghosh, N.K. (1967): Isoenzymes of human alkaline phosphatase. $A d v$. Clin. Chem., 10, 257-371.

9. Gerhard, W., Lykkegaard-Nielsen, M., Vagn-Nielsen, O., Olsen, J.S., and Statland, B.E. (1974): Routine measurements of liver and bone alkaline phosphatase in human serum. Differential inhibition by L-phenylalanine and carbamide. Clin. Chim. Acta, 53, 281-290.

10. AOAC (1984): Official Methods of Analysis (14th ed.), Association of Official Analytical Chemists, Washington, D.C.

11. Doumas, B.T., Watson, W.A., and Biggs, H.G. (1971): Albumin standards and the measurement of serum albumin with bromocresol green. Clin. Chim. Acta, 31, 87-107.

12. Steinberg, K.K., and Rogers, T.N. (1987): Alkaline phosphatase isoenzymes and osteocalcin in serum of normal subjects. Ann. Clin. Lab. Sci., 17, 241-249.

13. Kuwana, T., Sugita, O., and Yakata, M. (1988): Reference limits of bone and liver alkaline phosphatase isoenzymes in the serum of healthy subjects according to age and sex as determined by wheat germ lectin affinity electrophoresis. Clin. Chim. Acta, 173, 273-280.

14. Salah, L.A., Kheireldin, A.A., Mansour, M.M., and Hussein, F. (1976): Levels of some serum enzymes in patients with schistosomiasis. J. Trop. Med. Hyg., 79, 270-274. 